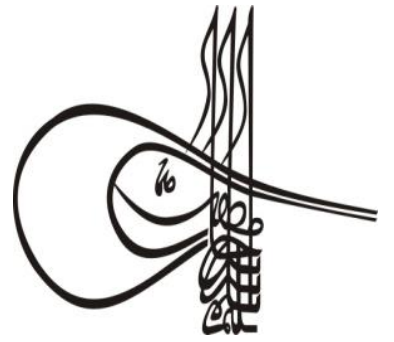

\section{Economics, Finance, Politics}

Volume 14 Issue 3, 2019, p. 921-933

DOI: 10.29228/TurkishStudies.30244

ISSN: 2667-5625

Skopje/MACEDONIA-Ankara/TURKEY

Research Article / Araştırma Makalesi

Article Info/Makale Bilgisi

Received/Geliș: 17.08.2019

VAccepted/Kabul: 30.09 .2019

Gor Report Dates/Rapor Tarihleri: Referee 1 (28.09.2019)-Referee 2 (28.09.2019)

This article was checked by intihal.net.

\title{
ÖRGÜTLERDE KARANLIK DÖRTLÜ - DARK TETRAD
}

\author{
İknur ÖZTÜRK*
}

\begin{abstract}
öz
Kişilik özellikleri örgütsel davranış bağlamında hem lider hem de çalışanlar için önemli bir yer oluşturmaktadır. Kişisel özellikler genelde normal kişilik özellikleri olarak incelenmektedir. Ancak son y1llarda yapılan çalışmalar, kişiliğin farklı özellikleri üzerinde yoğunlaşmaya başlamıştır. Üç kişilik yapılanması - Makyavelizm, Subklinik Narsisizm ve Subklinik Psikopati farklı dinamiklere sahip olmalarına rağmen, karanlık üçlü olarak literatüre girmiş ortak özelliklere sahip kişilik özellikleridir. Son zamanlarda yapılan çalıșmalar sadizm kișilik özelliklerinin de karanlık kişiliklerin özelliklerine dâhil edilmesi gerekliliğine dikkat çekerek Karanlık Dörtlü (Dark Tetrad) kavramını oluşturmuştur. Örgütlerde çalışanlar ve liderler bu kişilik özelliğine sahip olabilmektedir. Bu özelliğe sahip bireylerin örgütler için tehlike arz ettiğinden düşünülse de; son yıllarda bu özellikte olanların örgüt için faydalı olabileceği ile ilgili çalışmalar yapılmaktadır. Uluslararası alanlarda bu kavramlar incelenmeye başlanmış fakat Türkiye'de bu konuyla ilgili özellikle örgütsel davranış alanında yapılan çalışma sayısı kısıtlı kalmıştır. Bundan dolayı ülkemizde yapılan çalışmaların, bu kișilik kavramlarının örgütsel davranıș alanında nasıl bir tablo oluşturduğunun incelenmesi gerekmektedir. Örgütler bireylerden oluşmakta ve bu bireylerin kişilik özellikleri örgütlerin sürekliliği ve başarısı açısından önemli bir yer teşkil etmektedir. İşletmelerin önemli kaynağı olan insan faktörünün kişilik özellikleri işletme başarısı açısından önem arzetmektedir. Bu kişiliğe sahip bireylerin yönetilmesi işletme için faydalı olmaktadır. Bu çalışmada, karanlık üçlü ve karanlık dörtlü kavramının nasıl ortaya çıktığı literatür 1şığında incelenmiştir.
\end{abstract} Dörtlü

Anahtar kelimeler: Örgütsel Davranış, Karanlık Üçlü, Karanlık 


\title{
DARK TETRAD IN ORGANIZATIONS
}

\begin{abstract}
Personality traits are important for both leaders and employees in terms of organizational behavior. Personal traits are generally examined as normal personality traits. However, in recent years, studies have begun to focus on different characteristics of personality. Three personality structures - Machiavellianism, Subclinical Narcissism and Subclinical Psychopathy are personality traits that have common characteristics that have entered the literature as dark triad, although they have different dynamics. Recent studies have created the concept of Dark Tetrad, pointing out the need to include sadism personality traits in the characteristics of dark personalities. Employees and leaders in organizations can have this characteristic. Although it is thought that individuals with this feature are dangerous for organizations; in recent years, studies have been carried out on the fact that those with this feature may be beneficial for the organization. Begun to examine these concepts, especially in the international arena, but the number of studies in the field of organizational behavior on this issue in Turkey has been limited. Therefore, studies conducted in our country should examine how these personality concepts form a picture in the field of organizational behavior. Organizations consist of individuals and personality characteristics of these individuals constitute an important place in terms of continuity and success of organizations. Personality characteristics of human factor, which is an important source of enterprises, are important for business success. Managing individuals with this personality is beneficial for the business. In this study, the concept of the dark triad and dark tetrad is examined in the light of the literature.
\end{abstract}

\section{STRUCTURED ABSTRACT}

Personality traits are important for both leaders and employees in terms of organizational behavior. Personal traits are generally examined as normal personality traits. However, in recent years, studies have begun to focus on different characteristics of personality. Three personality structures - Machiavellianism, Subclinical Narcissism and Subclinical Psychopathy are personality traits that have common characteristics that have entered the literature as dark triad, although they have different dynamics. Recent studies have created the concept of Dark Tetrad, pointing out the need to include sadism personality traits in the characteristics of dark personalities.

Although they have different dynamics, the personality structures that make up the Dark Tetrad share many common features. Some of the basic behaviors are self-marketing, emotional coldness, hypocrisy, carelessness, manipulative behavior, selfishness and aggression. In the clinical literature, studies are conducted on the connections between these three features (Hart and Hare, 1998). Studies conducted in normal populations show that psychopathy features coincide with narcissism (Gustafson and Ritzer, 1995), Machiavellian characteristics correspond to psychopathy (McHoskey, Worzel and Szyarto, 1998),

Turkish Studies - Economics, Finance, Politics

Volume 14 Issue 3, 2019 
narcissism traits with Machiavelism (McHoskey, 1995). and moderately correlated studies (Lee and Ashton, 2005), they constitute the dark personality triad in the subclinically normal population. In recent years (Buckels et al., 2013), the Dark Tetrad has been formed upon the inclusion of sadism personality traits in the characteristics of dark personalities (Marcus and Zeigler-Hill, 2015).

Havelock Ellis used Narcissus myth to describe narcissism as a clinical phenomenon. The first conceptualization was made as intensive autoeroticism and dealing with its own erotic body (Ellis, 1989). Later, psychoanalysts have demonstrated that narcissism is not only manifesting pathologically, but it can also be a personality with arrogance and self-love.

Machiavellian concept was introduced to the literature in 1970 by Christie and Geis (1970). After making the statements in the book into question items, Christie conducted many interviews with individuals belonging to various groups and made a measure of personality traits in line with the results indicating reliable differences in the interviews. The basic idea of this feature is that her every way is possible to achieve the goal (Christie and Geis, 1970). It refers to individual differences that define behaviors such as cunning, manipulation, cheating and resorting to all kinds of immoral means to achieve the interests of the individual. Research conducted in laboratory and experimental environments, cold and manipulative behavior indicated that the most prominent indicators (Wilson, Near and Miller, 1996).

The first authors described psychopathy as an atypical form of mental illness in which rational abilities appeared normal, but daily behavior and social relationships were markedly impaired. In 1806 (Pinel, 1962), French physician Philippe Pinel first introduced the concept of "manie sans delire" which in his clinical studies revealed that intellectual capacities were normal and had no psychotic signs, but lack of intense aggression and moral values (Cleckey, 1976). In 1888, German psychiatrist Julius Koch first used the term "psychopathic" to describe the disease. Harvey Cleckley in his "Mask of Sanity" book described psychopathy as a pathological condition that is not psychotic but is formed by a combination of emotional and interpersonal characteristics. These individuals behave confident, aggressive, and well-adapted, but manifest themselves over time with their underlying pathology, behavior and attitudes.

In 1886, sexologist Kraft-Ebing used the word "sadism" for the first time in his book" Psychopathia Sexuals". In this book, the concept of Marquise de Sade was created to describe the individual's enjoyment of the pain or discomfort of others. Sadistic personality disorder was once described as a mental illness, but over time sadism has been recognized as a personality disorder or trait. In the Fifth Edition of the Diagnostic and Statistical Manual of Mental Disorders (DSM-5), it appears as a disorder of sadism and sexual sadism. The current definition of sadism is that the individual feels strong by using force for any living thing, harming him, and receiving pleasure from it. Not only physical power, violence, but also verbal and psychological violence. Sadism can be defined with features such as humiliating the other individuals, enjoying the psychological or physical anguish they suffer,

Turkish Studies - Economics, Finance, Politics

Volume 14 Issue 3, 2019 
lying to hurt others, making them do what they want by frightening them.

Employees and leaders in organizations can have this characteristic. Although it is thought that individuals with this feature are dangerous for organizations; in recent years, studies have been carried out on the fact that those with this feature may be beneficial for the organization. Begun to examine these concepts, especially in the international arena, but the number of studies in the field of organizational behavior on this issue in Turkey has been limited. Therefore, studies conducted in our country should examine how these personality concepts form a picture in the field of organizational behavior. Organizations consist of individuals and personality characteristics of these individuals constitute an important place in terms of continuity and success of organizations. Personality characteristics of human factor, which is an important source of enterprises, are important for business success. Managing individuals with this personality is beneficial for the business. In this study, the concept of the dark triad and dark tetrad is examined in the light of the literature.

Keywords: Organizational Behavior, Dark Triad, Dark Tetrad

\section{Giriş}

Kişilik üzerine yapılan çalışmalar, birçok toplumsal olgunun açıklanmasında yeni anlayışlar kazandırmıştır. Son yıllarda, toplumlarda giderek artmakta olan saldırganlık davranışlarının temelinde yatan bireysel farklılıkları inceleyen çalışmalar, kişilik özellikler üzerinde yoğunlaşmaktadır. Paulhus ve Williams (2002), kavramsal olarak farkl1, fakat ampirik olarak bir biriyle örtüşen kişilik değişkenlerinin üçlü takımı olan "Karanlık Üçlü” - "Dark Triad" kavramına dikkat çekmişlerdir. Üç kişilik yapılanması - Makyavelizm, Subklinik Narsisizm ve Subklinik Psikopati- her ne kadar teorik olarak farklı olsalar da, üç değişkenin mevcut ölçüleri bir biriyle büyük oranda örtüşme eğilimindedir. $\mathrm{Bu}$ üç kişilik yapılanmasının, ortak çekirdeği - duygusal manipülasyon ve empati eksikliği olarak yapılan birçok çalışma tarafından kanıtlanmıştır. Bu çalışmalar suç işlemiş veya klinik örneklemler ile değil, normal olarak adlandırılabilecek (öğrenciler, çalışanlar, memurlar, vb.) örneklemler ile yürütülmüştür. Bu kişilik yapılanmaları bireylerin, her hangi bir psikolojik veya kişilik bozukluğuna işaret etmediğinden dolayı subklinik olarak adlandırılmaktadır. Farklı dinamiklere sahip olmalarına rağmen, Karanlık Üçlü’yü oluşturan kişilik yapılanmaları birçok ortak özellik paylaşmaktadır. Farklı derecelerde de olsa üçü de sosyal olarak olumsuz özelliklere sahip, temel davranışlardan bazıları kendini-pazarlama, duygusal soğukluk, iki yüzlü olma, dikkatsizlik, manipülatif davranışlar, bencillik ve saldırganlık ifade edilmektedir. Klinik literatürde, bu üç özelliğin arasındaki bağlantılar üzerine çalışmalar yapılmaktadır (Hart ve Hare, 1998).

Normal popülasyonlarda yapılan çalışmalar göstermektedir ki, psikopati özellikleri narsisizm özellikleri ile (Gustafson ve Ritzer, 1995), Makyavelizm özellikleri psikopati ile (McHoskey, Worzel ve Szyarto, 1998), narsisizm özellikleri Makyavelizm ile (McHoskey, 1995) örtüşmekte, üç özelliğin bir biriyle düşük ve orta derecede korelasyon gösterdiğini kanıtlayan çalışmaların 1şığında (Lee ve Ashton, 2005), subklinik olarak normal popülasyonda, karanlık kişilik üçlüsünü oluşturmaktadırlar. Son yıllarda yapılan çalışmalar (Buckels vd., 2013) sadizm kişilik özelliklerinin de karanlık kişiliklerin özelliklerine dahil edilmesi üzerine Karanlık Dörtlü oluşturulmuştur (Marcus ve ZeiglerHill, 2015). 
Bu çalışmanın amacı; günümüz işletmelerinin sahip olduğu en önemli kaynak olarak insan ve onların kişilik özelliklerinin örgütsel davranış bağlamında incelemeye çalışmaktır.

\section{Karanlık Üçlü Ve Karanlık Dörtlü Öğeleri}

Karanlık üçlü; Makyavelizm, Subklinik Narsisizm ve Subklinik Psikopati olarak farklı dinamiklere sahip olmalarına rağmen, karanlık üçlü olarak literatüre girmiş ortak özelliklere sahip kişilik özellikleridir. Yapılan çalışmalar karanlık üçlü ögelerine sadizm kişilik özelliklerini de dâhil ederek Karanlık Dörtlü (Dark Tetrad) kavramını oluşturmuşlardır. Karanlık üçlü ve karanlık dörtlüyü oluşturan ögeler aşağıda ayrıntılı olarak açıklanmıştır.

\subsection{Narsisizm}

Havelock Ellis, Narkissos mitini, narsisizmi, klinik bir olgu olarak tanımlamak için kullanmıştır. İlk kavramlaştırma, yoğun otoerotizm ve kendi erotik bedeniyle uğraş olarak yapılmıştır (Ellis, 1989). Daha sonra, psikanalistler, narsisizmi, sadece patolojik olarak tezahür etmediğini, aynı zamanda kibir ve kendini sevme özellikleri olan kişilik olabileceğini ortaya koymuşlar. 1914 yılında Freud "Narsizm Üzerine" makalesinde hem normal hem patolojik narsisizmi ele almıştır, onu takiben Otto Rank 1929 ve Alfred Adler 1927 y1lında bugün narsisizm başlığı altında ele alabileceğimiz makaleler yazarak, narsisizmi bireyin öz değeri ve öz güveni düşük olduğu zaman, koruyucu bir mekanizma olarak işlediğini varsaymışlardır. Wilhelm Reich (1933) narsistik kişilik fikrini genişleterek, "fallik narsistik kişilik" terimini önermiş; Karen Horney (1939) "agresif-taşkın" "mükemmeliyetçi-kibirli" narsistik yapılanmalarını literatüre katmıştır (McWilliams, 1994). Çağdaş araştırmacılar, narsisizmi normal ve patolojik (Rogoza vd., 2018), büyüklenmeci ve kırılgan narsisizm (Wink, 1991) olarak kavramsallaştırmaktadırlar. Büyüklenmeci narsisizmin iki boyutu mevcut: Birinci boyut genel hatlarıyla, abartılı öz değer duygusu, kendini yücelten, sosyal hayranlığı amaçlayan benliği güçlendiren, benliğe yönelik çabayı ve büyüklenmeci fantezileri kapsamaktadır. Diğer boyut, narsistik rekabet, benliği koruyan, narsisizmin antagonist yönüdür. Ötekileri değersizleştirme, üstün olma çabası, benliğe yönelik tehditleri azaltmayı amaçlayan ve sosyal çatışmalarla sonuçlanabilecek olan olumsuz davranışlardır (Back vd. 2013). Bununla birlikte narsistik rekabet, düşük benlik saygısı, dürtüsellik, kıskançlık, yalnızlık, düşük empati, düşük güven ve affedebilme eksikliği gibi negatif bağıntılarla ilişkilidir ve temel olan, herkesten daha güçlü olmak, motivasyonu tarafindan yönlendirilmektedir (Geukes vd., 2016). Kişilik üzerine çalışmalar yapan psikologlar hafif derecede olan narsisizm özelliklerinin psikolojik bir bozukluğa işaret etmediğini, bir kişilik yapılanması olarak kabul etmektedirler (Rhodewalt ve Peterson, 2009). Watson, Grisham, Trotter ve Biderman (1984), zaman zaman herkesin narsistik davranışlar gösterdiğini, ancak bu narsistik kişilik bozukluğu tanısı için yeterli olmadığını savunmuştur. Amerikan Psikiyatri Birliği'ne (2013) göre, bir birey Narsistik Kişilik Bozukluğu tanısı alabilmek için DSM - V el kitabında listelenen dokuz kriterden beşine sahip olmalidir.

\subsection{Makyavelizm}

Makyavelizm kavramı, Christie ve Geis (1970) tarafından literatüre 1970 y1lında kazandırılmıştır. Christie, kitapta yer alan ifadeleri, soru maddeleri haline getirdikten sonra, çeşitli gruplara ait bireylerle birçok mülakatlar gerçekleştirmiş ve yapılan görüşmelerde güvenilir farklılıklar işaret eden sonuçların doğrultusunda, bir kişilik özellikleri ölçüsü haline getirmiştir. Bu özelliğin temel fikri "Amaca ulaşmak için her yol mübahtır" (Christie ve Geis, 1970). Bireyin çıkarlarına ulaşmak için kurnazlık, manipülasyon, hile ve her türlü ahlaki olmayan yollara başvurmak gibi davranışları tanımlayan bireysel farklılıkları ifade etmektedir. Yapılan araştırmalar, laboratuar ve deneysel ortamlarda yürütülmüş, soğuk ve manipülatif davranışların göstergelerin en belirgin olarak çıktığını belirtmişler (Wilson, Near ve Miller, 1996). Herkes bir dereceye kadar manipülasyon yeteneğine sahiptir. Aslında, önceki araştırmalar, insanın hayatta kalması için değerli bir özellik olduğunu ve "doğal seleksiyonun, diğer bireylerin davranışlarını başarılı bir şekilde manipüle eden bireyleri 
desteklediğini” ileri sürmüşlerdir (Dawkins ve Krebs, 1978). Bu, Makyavelizm'in dinamiklerini araştıran ve bunun gelişmiş bir zekâ olduğunu keşfettiği ve "daha yüksek sosyal ve üreme başarısı" elde etmek için hayati bir strateji olduğunu keşfeden Gavrilets ve Vose (2006) tarafindan da desteklenmektedir. Wastell ve Booth (2003), Makyavelistlerin diğerleriyle duygusal olarak bağlantı kuramadıklarını ve bu nedenle insanlara nesne ya da bir amaç olarak davrandıklarını belirtmektedirler. $\mathrm{Bu}$, ötekileri kötüye kullanma eğilimleri (Kiazad vd. 2010) ve manipülatif stratejileri kullanmaları (Kessler vd. 2010) ile birlikte, sosyal hayatta güç sağlamada usta olmalarını sağlamaktadır. Makavyelist kişilik, birbiriyle ilişkili üç değer kümesi ile tanımlanabilir. Bunlar; manipülatif taktiklerin, öteki insanları yönetmek için, etkili olduğuna dair inanç; insanın doğasına dair sinik bakış açısı; menfaatleri, kurallar ve prensiplere üstün tutma eğilimidir. Fehr, Samson, ve Paulhus (1992) tarafından yapılan geniş literatür incelemeleri, Makyavelist olarak tanımlanan bireylerin insanlara yönelik olumsuz bakış açısına sahip olduğu, etik dışı seçim ve davranışlarının sıklıkla yapılması özelliklerinin doğrular niteliktedir.

\subsection{Psikopati}

İlk yazarlar, psikopatiyi, rasyonel yetilerinin normal göründüğü, ancak günlük davranış ve sosyal ilişkilerin belirgin bir şekilde bozulduğu atipik bir akıl hastalığı şekli olarak nitelendirilmişlerdir. Fransız Doktor Philippe Pinel 1806 y1lında (Pinel, 1962) ilk kez, "manie sans delire" (delirmeden çıldırma) kavramını ortaya koymuştur, yaptığı klinik çalışmalarda, entelektüel kapasitelerin normal olan ve her hangi bir psikotik bulgusu olmayan, ancak yoğun agresyonun ve ahlaki değerlerin yokluğunu tespit etmiştir (Cleckey, 1976). 1888 yılında Alman psikiyatrist Julius Koch, hastalığı tanımlayan "psikopatik" terimini ilk kez kullanmıştır. Harvey Cleckley "Mask of Sanity" kitabında psikopatiyi psikotik olmayan, fakat duygusal ve kişilerarası özelliklerin bir araya gelmesiyle oluşan patolojik bir durum olarak tanımlamıştır. Bu bireyler, kendinden emin, girişken ve iyi uyum sağlayan olarak davranmaktadırlar, fakat altta yatan patoloji, davranış ve tutumları ile zaman içerisinde kendini göstermektedir. Cleckley (1976), psikopatik kişiliğe sahip olan bireylerin doğalarını acımasız, tehlikeli ve de saldırgan olarak nitelendirmemektedir. Bazen tekrarlayan şiddet içerikli davranışlarda bulunsa da, her zaman fiziksel olarak zarar vermeyen, amaçlı şiddetten ziyade, dürtüsel ben-merkezciliğin ürünü olarak tanımlanmıştır. Literatüre bakıldığında, birçok "başarılı psikopat" örneği doktor, profesör, asker vb. olarak mevcuttur. Yapılan çalışmalar, psikopatiye neyin sebep olduğu ile ilgili anlaşmazlıklar üzerinde durmaktadır. Alternatif bakış açılarını bir araya getiren ve en son kavramsallaştırmadan biri Triarchic Model olarak bilinen, 2009 yılında Patrick, Flowes ve Krueger tarafından yapılmıştır. Bu model psikopatiyi, ayrılabilir üç semptomlar bileşeni çerçevesinde incelemekte (Disinhibisyon, Gözüpeklik ve Alçaklık/Adilik), bu model farklı psikopati anlayışları için temel yapı taşları olarak görülebilir (Patrick, Flowes ve Krueger, 2009). Psikopati "düşük dürtü ve kaygı ile birlikte yüksek dürtüsellik ve heyecan arayışı" ile nitelendirilir. Psikopatlar aynı zamanda duygusal, manipülatif ve son derece dişlayıcı olarak tanımlanmıştır. (Hodson, Hogg ve MacInnis, 2009).

\subsection{Sadizm}

Seksolog Kraft-Ebing'in 1886 yılında "Psychopathia Sexuals" adlı kitabında ilk kez "sadizm" kelimesini kullanmıştır. Bu kitapta, bireyin başkalarının acısından ya da rahatsızlığından zevk almayı tanımlamak için bu kavramı Marquise de Sade adından oluşturmuştur. Sadist kişilik bozukluğu bir zamanlar zihinsel bir hastalık olarak tanımlanıyordu, ancak zamanla sadizm bir kişilik bozukluğu ya da özelliği olarak kabul edilmiştir. Ruhsal Bozuklukların Tanısal ve Sayımsal El Kitabı Beşinci Baskısında (DSM-5), sadizm - cinsel sadizm bozukluğu olarak yer almaktadır. Sadizmin güncel tanımı, herhangi bir canlıya yönelik güç kullanarak, zarar vererek, bireyin kendisini güçlü hissetmesi ve bundan alınan haz şeklindedir. Sadece fiziksel güç, şiddet değil, sözel ve psikolojik şiddet de söz konusu olabilmektedir. Öteki bireyleri küçük düşürmek, çektikleri psikolojik veya fiziksel ıstıraptan zevk almak, ötekilere zarar vermek için yalan söylemek, korkutarak istediğini yaptırmak gibi 
özellikler ile sadizm tanımlanabilir. Sadizmi cinsel veya suç bağlamında düşünmemize rağmen, sadist eğilimler günlük yaşamda yaygındır. Toplumsal normlara uymadıkları için, uyguladıkları şiddetin topluma zarar verdiği için, zamanla sadizm kavramı yerini sosyopat kavramına bırakmıştır. Tüm sadistik eylemler cinsel içerikli değildir. Yapılan bir çalışmada (Buckels vd., 2013), Everyday sadism olarak tanımlanan Günlük Sadizm kavramı ortaya çıkmıştır, empati eksikliği olan bu bireylerin başkalarına zarar vermek için iç motivasyonları mevcut, sosyopatlardan farklı olarak, şiddet temelli davranışlarının toplum açısından onaylanmadığı, cezai sorumluluğu olduğu durumlarda, bu davranışları sergilememektedirler. Sosyopatlar ile empati eksikliği açısından çok benzemelerine rağmen, onlar kadar toplum için tehlikeli değillerdir. Şiddeti, sadece toplumda kabul edilebildiği formlarda uygulamaktadırlar. Gündelik sadizmin tezahür edebilmesi için, hem sosyopatik kişilik yapılanmasının hem de bireyin içinde olduğu durumun baskı yapması gerekmektedir (Buckels vd. 2013).

\section{Karanlık Üçlüden Karanlık Dörtlü'ye Geçiş}

Paulhus ve Williams (2002), incelemesinde ele alınan kişilik üçlüsünü tanımlamak için 'karanlık' sıfatını seçmişlerdir. O zamanlar, bu kavramın uygun görünmesinin nedeni Dark Triad bileşeni sosyal açıdan rahatsız edici davranışları tanımlıyor olmasıydı. Bununla birlikte her bir özelliğin uyumlu ve uyumsuz unsurları içerdiğine işaret edilmektedir. Bu bulgular da kişilik özelliklerinin her iki boyutunun da var olduğuna dair evrimsel argümanlarla tutarlıdır (Penke, Denissen ve Miller, 2007). Karanlık kişilikler terimi, subklinik aralıktaki bir dizi sosyal açıdan rahatsız edici özellikten oluşturulmuştur. Klinik veya adli ilgiyi çekecek kadar aşırı olmayan, günlük çalışma ortamlarında, eğitim ortamlarında ve daha geniş topluluklarda kendini göstermektedir.

Sadizm, psikopatik, narsisistik ve Makyevelist özellikleriyle pek çok benzerliği paylaştığı için şimdi karanlık tetrad içinde olması önerilen yeni bir özelliktir. Sadizm'den yüksek puan alanların, başkalarının acılarını sevdiği, saldırgan eğilimleri ve iktidar arzusu olduğu ifade edilmektedir. Masum bireylere karşı düşmanca eylemlerde bulunmak için harcanan zaman ve enerjiyle bağlantılı tek karanlık kişilik özelliğidir (Buckels vd., 2013).

Hem teorik hem de ampirik örtüşmeyi açıklayan ortak özellik başkalarına karşı empati eksikliğidir. Her birinin kendine has özellikleri olduğu gibi, bu dört kişilik özellikler oldukça farklı bir şekilde ortaya çıkmaktadır. Ötekilerin sadece kendilerini beğenmelerine yönelik arzusu olduğu için narsistlerin empati eksikliği vardır. Stratejik Makevialist, sadece kendi çıkarlarını gözetmektedir. Buna karşılık, psikopatlar, başkalarının incinmesi durumunda çok az empati göstererek, istediklerini zorla alırlar. Gündelik sadist aslında diğer insanların acı çekmesine neden olma firsatları arar (Jonason, vd., 2011). Dört özellik orta düzeyde birbiriyle ilişkilidir ve her biri bir dereceye kadar saldırganlık ve ikiyüzlülük içermektedir (Paulhus ve Williams, 2002).

Daha fazla ampirik araştırmaya ihtiyaç duyulmasına rağmen mevcut çalışmaların elde ettikleri bilgiler ışığında, özellikle çevrimiçi davranışları araştırırken Karanlık Üçlü’ye ek olarak sadistik özelliklerinin etkin olması, gündelik sadizmi bu kişilik yapılanmalarına eklenmesinin önemini ortaya koymuştur (van Geel, Goemans, Toprak, ve Vedder, 2017).

Psikopati, duygusallık ve kişilerarası manipülasyonun yanı sıra düzensiz, antisosyal ve itici eylemlere yönelik davranışlar olarak da tanımlanmaktadır (Paulhus, Hemphill ve Hare, 2012). Makyavelizm, stratejik kişilerarası manipülasyon ve alaycı dünya görüşleri ile karakterizedir. Sadizm, başkalarının aşağılanmasını, zulüm ve alçaltıcı davranış biçimlerinin yanı sıra, kişisel zevk için başkalarına fiziksel, cinsel veya psikolojik olarak zarar vermeyi içerir (OMera, Davies ve Hammond, 2011). Bu kişilik özellikleri arasında benzerlikler olsa da (örneğin, kişilerarası manipülasyon narsisizm, psikopati ve Makyavelizm arasında paylaşılan ortak bir özelliktir) ancak önemli farklılıklar olduğu için ampirik olarak farklı yapıları temsil ettiği kabul edilebilir. Örneğin, sadizm, genel saldırganlık ve başkalarına zarar vermek için istekli olmakla ilişkiliyken, narsisizm, psikopati ve

Turkish Studies - Economics, Finance, Politics

Volume 14 Issue 3, 2019 
Makyavelizm, yalnızca spesifik bağlamlarda saldırganlıkla ilişkilidir (Buckels vd. 2013). Her ne kadar Makyavelizm, tek boyutlu bir yapı olarak kabul edilse de, narsisizm ve psikopati, altta yatan fasetlerden oluşan heterojen yapılar olarak kabul edilir (Emmons, 1984). Bu yönleri ayrı ayrı düşünmek önemlidir, çünkü baskınlık ve antisosyal davranışlar gibi kişilerarası eğilimlerle olan ilişkilerinde farklılık gösterdiği bulunmuştur (Williams vd. 2007).

Tek tek incelenen karanlık kişilik özelliklerinin empati eksikliği üzerine birçok bulguya rastlanmış, fakat bu tür yorumların kesin bir sav olarak kabul edilmesi çok olası değildir, çünkü karıştırıcı, başka karanlık özellikler bu çalışmalarda dışlanmamıştır. Fakat Karanlık Üçlü olarak yapılan çalışmalar, bize göstermektedir ki, üç karanlık özellik de düşük duygusal empati gösterirken, bilişsel empatini konusunda herhangi bir düşüş ve de yükseliş göstermemektedir. Narsisizm ile duygusal empati ve öngörü arasında negatif ilişki bulunmuş, kognitif empati ile düşük güçte pozitif ilişkinin varlığı bulunmuştur (Wai ve Tiliopoulos, 2012).

Birincil psikopatik özelliklere ve Makyavelizm'e sahip bireyler, bir duygu tanımlama görevinde daha düşük performans sergilerken, narsisistik bireyler, öfkeli yüz ifadelerini tanımlamakta daha başarılı olmuşlardır. Bununla birlikte, sonraki bir çalışma, Karanlık Triad özelliklerinin, narsisizm ile duygusal empati arasındaki ilişki eksikliği dışında, hem duygusal hem de bilişsel empati ile negatif korelasyon gösterdiğini göstermiştir. Son olarak, sadece psikopati hem empati tiplerini hem de narsizmi öngören, duygusal empatinin olumlu bir göstergesi olarak ortaya çıkmıştır (Jonason ve Krause, 2013).

Örgütsel davranış bağlamında Karanlık Dörtlü kişiliklere bakıldığında, "toksik lider", "kötü patronlar", "takım elbiseli yılanlar" kavramları en çok bu kişilik tiplerine uygundur (Furnham, vd., 2013). Fakat sadece liderler değil, çalışanlar da bu tip kişiliklerine sahip olabilirler. Uzun zaman boyunca Karanlık Üçlü’yü oluşturan kişilik tiplerinin örgütler için bir tehlike arz ettiği düşünülmüştür, fakat son yıllarda, bu kişilik özelliklerinin örgüt için nasıl olumlu ve faydalı bir hale çevrilebileceği konusunda çalışmalar yapılmıştır. Furnham vd. (2013) Karanlık Üçlü yapılanmasına sahip bireylerin zeka ve fiziksel çekicilik gibi faktörlerin, lider olma pozisyonuna yükselmesine yardımcı kriterler olduğunu ifade etmektedirler. Hogan'ın ifadesi ile, Karanlık Üçlü bireyleri, “örgütü yönetir, fakat örgüt ile haşır neşir olmaz” (Hogan, Barrett ve Hogan 2007). Bazı çalışmalar (Babiak ve Hare, 2006) başarılı psikopatlar ve başarılı narsistler (Chatterjee ve Hambrick, 2007) üzerine çalışmalar yapmışlardır. Bu bireyler bazı durumlarda olumlu olarak gelişse de, zaman içinde eylemlerinden dolayı itibarlarını kaybetmektedirler. Farklı örgüt davranışları yakın zamanda, öğrenci örneklemleri ile çeşitli senaryolara nasıl tepki vereceklerini tahmin etmelerini isteyerek simüle edilmeye çalışmaktadır (Jonason, Slomski ve Partyka, 2012). Narsistler yumuşak manipülasyon taktikleri kullandıklarını iddia ederken, psikopatlar zor kullanarak uygulanan taktikleri seçmektedir. Her zamanki gibi, Makyavelistler en esnek olanı olarak, hem yumuşak hem de sert taktikler seçmişlerdir.

Karanlık kişilik üçlünün bileşenleri arasında önemli benzerlikler olsa da, bu bileşenler arasındaki önemli farklılıkları kabul etmeliyiz. Bu nedenle, karanlık üçlü kişilik yapılanmasının diğer yapılarla geniş ve farklı bağları nedeniyle, karanlık özelliklerin sayısı üçten fazla olabileceği uzun zamandan beri varsayılmaktadır. Sadizm'in dâhil edilmesiyle, Karanlık Üçlü'yü, Karanlık Dörtlü'ye genişletmek son zamanların en büyük değişikliği olarak kabul edilebilir. Sadist insanlar her zaman zalimce veya şiddet içeren günlük faaliyetlerde bulunma fırsatlarını aramaktadırlar. Kişilerarası ilişkilerinde başkalarına aldırış etmeyen psikopatik insanlarla karşılaştırıldığında, sadist bireylerin bencilce hedefleriyle başkalarına zarar verebileceği belirtilmektedir.

Çeşitli araştırmalar, sadizm ve Karanlık Triad özelliklerinin, başta psikopati olmak üzere, empati eksikliği ve duygusal dahil olmaya, duygu paylaşımına hazır olma eksikliği, başkalarına acı çekmek ve antisosyal davranışlarla bağlantılı eylemler gibi birçok ortak özelliğe sahip olduğunu göstermiştir (Kirsch ve Becker, 2007). Aynı zamanda, bazı bulgular bunların bağlantılı olduğunu ancak farklı özellikler olduğunu göstermektedir (Mokros, Osterheider, Hucker ve Nitschke, 2011). 
Reidy vd. (2011), sadizmin, psikopatiden ayrı olarak, laboratuar ortamında kışkırtılmamış saldırganlığı yordadığını bulmuşlardır. İki çalışma, sadizmin, Dark Triad özelliklerinin değişimi göz önüne alındığında bile diğer canlılara zarar vermeyi amaçlayan davranışı önemli ölçüde yordadığını göstermiştir (Buckels vd., 2013). Mahkûm olan bireyler ile yapılan araştırmalar, sadizmi içeren acımasız ve ahlak yönünden yıkıcı olan özellikler, tekrar suç işleme eylemini, psikopati özelliklerinden daha güçlü bir şekilde yordadığını göstermiştir (Malamuth, 2003). Bu nedenle, Chabrol ve diğer araştırmacıların, " Karanlık Tetrad " in yeni yapısı içindeki diğer üç özelliğe sadizm eklemesi önerisi makul gözükmektedir (Buckels vd, 2013; Chabrol vd, 2009; Paulhus, 2014).

\section{Sonuç}

Karanlık Dörtlü ve onun öncüsü Karanlık Üçlü - son yıllarda bir çok araştırmaya konu olmuştur, fakat bu kişilik özelliklerinin sabit bir karanlık kişilik yapılanması olarak kabul edilmesi çok olası değildir, çünkü yalnızca kısıtlı sayıda kişilik özellikleri ile sınırlıdır (düşmanlık ve manipülasyon ile alakalı olanlar). Karanlık kişilik özelliklerinin incelenmesi Karanlık Tetrad'da yer alan özelliklerin ötesinde, daha geniş kapsamlı çalışmaların sürdürülmesi yararlı olacaktır.

Uluslararası alanda işyerinde Karanlık Triad ile ilgili araştırmalar oldukça hızlı devam etmektedir (Jonason, Slomski ve Partyka, 2012; O’Boyle, Forsyth, Banks ve McDaniel, 2012; Wu ve LeBreton, 2011). Tipik olarak, aracı tarafı işe alınmalarını kolaylaştıran bireylerdir. Bununla birlikte, alt akışta, uygun taramalarla beklenebilecek ters üretken davranışlar sergilerler. En önemli işyeri uygulamaları arasında, toksik liderlerin, hasara yol açmadan önce tespit edilmesi yer almaktadır (Harms, Spain, ve Hannah 2011; Hogan, 2007; O’Boyle vd. 2012). Bazı mesleklerde, fiili fiziksel zarar veya suçluluk, istemeden karanlık kişiliklerin işe alınmasından kaynaklanabilir. Özsoy ve Ardıç (2017), karanlık üçlünün iş tatminine etkisini, Aydoğan ve Serbest (2016) işyerinde karanlık üçlü, Özsoy ve Ardıç ve Balaban (2017), karanlık üçlü ve örgütsel bağlllık ilişkisini, Özdemir ve Atan (2018), karanlık üçlünün örgütsel muhalefete etkisini incelemiştir. Bu da göstermektedir ki; yerli literatürde yapılan çalışmalar daha çok karanlık üçlüyü kapsamaktadır.

Karanlık tetrad'ın teorik düzeyde formülasyonu yapılmış olmasına karşın, bu formülasyonun ampirik olarak kabul edilmesi için hala yeterli ampirik kanıt yoktur. Elbette, günlük sadizmi değerlendirmek için çeşitli araçların mevcut, ancak karanlık üçlünün karanlık tetrad'a ampirik olarak gelişmesi için, sadizm bileşeninin ayrı ölçülmesi faydalı olmayacaktır. Karanlık triad özellikleri bağlamında değerlendirilmeli ve daha da önemlisi, karanlık tetradın geçerliliğini ve güvenilirliğini değerlendirmek için karanlık tetrad özellikleri kavramını doğrulamadaki rolü değerlendirilmelidir. Bilindiği gibi, karanlık üçlünün her bir bileşeni kendi başına bir kişilik yapılanması, fakat bir bütün olarak karanlık üçlü olmasının sebebi, bu yapılanmalarının bir biriyle örtüşmesidir, aynı bulguların da sadizm için daha geniş popülasyonlarında, karanlık dörtlü olarak ölçüldüğünde, Karanlık Tetrad'ın geçerliliği ve güvenirliliği yüksek olarak kabul edilmiş olabilir.

Sonuç olarak işletmelerin önemli kaynağı olan insan faktörünün kişilik özellikleri işletmelerin başarısı için önemli bir yer oluşturmaktadır. Bu kişilik özelliğine sahip bireylerin yönetilmesi ve işletme için faydalı hale getirilmesi gerekmektedir. Uluslararası alanda karanlık üçlü ve karanlık dörtlü ile yapılan çalışmalar devam etmekte iken bu Türkiye'de fazla rağbet görmemiştir. Diğger yapılacak olan çalışmalara bu kavramların örgütsel davranış konuları bağlamında incelenmesi ve özellikle karanlık dörtlü açısından irdelenmesi önerilmektedir.

\section{KAYNAKÇA}

Adler, A. (1927). Individual psychology. The Journal of Abnormal and Social Psychology, 22(2), 116.

American Psychiatric Association. (2013). Diagnostic and statistical manual of mental disorders (5th ed.). Arlington, VA: American Psychiatric Publishing.

Turkish Studies - Economics, Finance, Politics

Volume 14 Issue 3, 2019 
Aydoğan, E., \& Serbest, S. (2017). İş Yerinde Karanlık Üçlü: Bir Kamu Kuruluşunun İç Denetim Biriminde Araştırma. Saylştay Dergisi. 101, 97-101.

Babiak, P., \& Hare, R. D. (2006). Snakes in suits: When psychopaths go to work. New York, NY: Harper Collins.

Back, M. D., Küfner, A. C. P., Dufner, M., Gerlach, T. M., Rauthmann, J. F., \& Denissen, J. J. A. (2013). Narcissistic admiration and rivalry: Disentangling the bright and dark sides of narcissism. Journal of Personality and Social Psychology, 105, 1013-1037.

Buckels, E. E., Jones, D. N., \& Paulhus, D. L. (2013). Behavioral confirmation of everyday sadism. Psychological Science, 24, 2201-2209.

Chabrol, H., Van Leeuwen, N., Rodgers, R., \& Séjourné, N. (2009). Contributions of psychopathic, narcissistic, Machiavellian, and sadistic personality traits to juvenile delinquency. Personality and Individual Differences, 47, 734-739.

Chatterjee, A., \& Hambrick, D. C. (2007). It's all about me: Narcissistic chief executive officers and their effects on company strategy and performance. Administrative Science Quarterly, 52, 351-386.

Christie, R., \& Geis, F. L. (Eds.). (1970). Studies in Machiavellianism. San Diego, CA: Academic Press.

Cleckley H. (1976) The mask of sanity: An attempt to clarify some issues about the so-called psychopathic personality. 5. St Luis, Mo: Mosby-Year Book Inc.

Dawkins, R. \& Krebs, J. R. (1978) Animal signals: Information or manipulation? In: Behavioural ecology: An evolutionary approach, ed. J. R. Krebs \& N. B. Davies, pp. 282 -309. Basil Blackwell.

Ellis, A. (1989). Comments on Zieglers chapter. In M. E. Bernard \& R. Di Giuseppe (Eds.). Inside rationalemotive therapy: A criticai appraisal of the theory and therapy of Albert Ellis. San Diego, CA: Academic Press.

Emmons, R.A. (1984). Factor analysis and construct validity of the Narcissistic Personality Inventory. Journal of Personality Assessment, 48, 291- 300.

Fehr, B., Samson, D., \& Paulhus, D. L. (1992). The construct of Machiavellianism: Twenty years later. Advances in personality assessment. vol. 9. Advances in personality assessment (pp. 77116). Hillsdale, NJ: Lawrence Erlbaum Associates, Inc.

Furnham, A., Richards, S. C, \& Paulhus, D. L. (2013). The Dark Triad of personality: A 10-year review. Social and Personality Compass, 7, 199-216.

Freud, S. (1914). Narsizm üzerine ve Schreber vakası (2. bs., çev. B. Büyükal ve SM Tura). İstanbul: Metis Yayınlart.

Gavrilets, S., \& Vose, A. (2006). The dynamics of Machiavellian intelligence. Proceedings of the National Academy of Sciences, 103(45), 16823-16828.

Geukes, K., Nestler, S., Hutteman, R., Dufner, M., Küfner, A. C. P., Egloff, B., . . . Back, M. D. (2016). Puffed up but shaky selves: State self-esteem level and variability in narcissists. Journal of Personality and Social Psychology, 12(5):769-78.

Gustafson, S. B., \& Ritzer, D. R. (1995). The dark side of normal: A psychopathy-linked pattern called aberrant self-promotion. European Journal of Personality, 9, 147-183. 
Harms, P. D., Spain, S. M., \& Hannah, S. T. (2011). You underestimate the power of the dark side. Presented at the Society for Industrial and Organizational Psychology. Chicago, IL.

Hart, S., \& Hare, R. D. (1998). Association between psychopathy and narcissism: Theoretical views and empirical evidence. In E. F. Ronningstam (Ed.), Disorders of narcissism: Diagnostic, clinical, and empirical implications (pp. 415-436). Washington, DC: American Psychiatric Press

Hodson, G., Hogg, S. M., \& MacInnis, C. C. (2009). The role of "dark personalities" (narcissism, Machiavellianism, psychopathy), Big Five personality factors, and ideology in explaining prejudice. Journal of Research in Personality, 43, 686-690.

Hogan, J., Barrett, P., \& Hogan, R. (2007). Personality measurement, faking, and employment selection. Journal of Applied Psychology, 92(5), 1270-1285.

Hogan, R. (2007). Personality and the fate of organizations. Mahwah, NJ. Lawrence Erlbaum Associates.

Horney, K. (1939). What is a neurosis?. American Journal of Sociology, 45(3), 426-432.

Jonason, P. K., \& Krause, L. (2013). The emotional deficits associated with the Dark Triad traits: Cognitive empathy, affective empathy, and alexithymia. Personality \& Individual Differences, $55,532-537$.

Jonason, P. K., Kavanagh, P., Webster, G. D., \& Fitzgerald, D. (2011). Comparing the measured and latent Dark Triad: Are three measures better than one? Journal of Methods and Measurement in the Social Sciences, 2, 28-44.

Jonason, P. K., Slomski, S., \& Partyka, J. (2012). The Dark Triad at work: How toxic employees get their way. Personality and Individual Differences, 52, 449-453.

Kraft-Ebing, R. V. (1886). Psychopathia Sexualis: Eine Klinisch-Forensische Studie, Enke, Stuttgart, Germany.

Kessler, R. C., McLaughlin, K. A., Green, J. G., Gruber, M. J., Sampson, N. A., Zaslavsky, A. M., ... \& Benjet, C. (2010). Childhood adversities and adult psychopathology in the WHO World Mental Health Surveys. The British Journal of Psychiatry, 197(5), 378-385.

Kiazad, K., Restubog, S. L. D., Zagenczyk, T. J., Kiewitz, C., \& Tang, R. L. (2010). In pursuit of power: The role of authoritarian leadership in the relationship between supervisors' Machiavellianism and subordinates' perceptions of abusive supervisory power. Journal of Research in Personality, 44, 512-519.

Kirsch, L. G., \& Becker, J. V. (2007). Emotional deficits in psychopathy and sexual sadism: Implications for violent and sadistic behavior. Clinical Psychology Review, 27, 904-922.

Lee, K., \& Ashton, M. C. (2005). Psychopathy, Machiavellianism, and narcissism in the five-factor model and the HEXACO model of personality structure. Personality and Individual Differences, 38, 1571-1582.

Malamuth, N. M. (2003). Criminal and non-criminal sexual aggressors: Integrating psychopathy in a hierarchicalmediational confluence model. Annals of the New York Academy of Sciences, 989, 33-58.

Marcus, D. K., \& Zeigler-Hill, V. (2015). A big tent of dark personality traits. Social and Personality Psychology Compass, 9, $434-446$.

McHoskey, J. (1995). Narcissism and Machiavellianism. Psychological Reports, 77, 755-759. 
McHoskey, J. W., Worzel, W., \& Szyarto, C. (1998). Machiavellianism and psychopathy. Journal of Personality and Social Psychology, 74, 192-210.

McWilliams, N. (1994). Psychoanalytic Diagnosis: Understanding Personality Structure in the Clinical Process. New York: Guilford Press.

Mokros, A., Osterheider, M., Hucker, S. J., \& Nitschke, J. (2011). Psychopathy and sexual sadism. Law and Human Behavior, 35, 188-199.

O’Boyle, E. H., Jr., Forsyth, D. R., Banks, G. C., \& McDaniel, M. A. (2012). A meta-analysis of the dark triad and work behavior: A social exchange perspective. Journal of Applied Psychology, 97, 557579 .

O'Meara, A., Davies, J., \& Hammond, S. (2011). The psychometric properties and utility of the short sadistic impulse scale (SSIS). Psychological Assessment, 23, 523-531.

Özdemir, B., \& Atan, E. (2018). Karanlık Üçlünün Örgütsel Muhalefete Etkisi: Bir Yapısal Eşitlik Modeli. Türkiye İktisadi Girişim ve İş Ahlâkı Derneği, 11(2), 275-298.

Özsoy, E., \& Ardiç, K. (2017). Karanlık Üçlü'nün (Narsisizm, Makyavelizm ve Psikopati) İş Tatminine Etkisinin İncelenmesi. Yonetim ve Ekonomi, 24(2), 391-406.

Özsoy, E., Ardıç, K., \& Balaban, Ö. (2017, October). Karanlık Üçlü’nün Örgütsel Bağl1lığa Etkisinin İncelenmesi. In ICPESS (International Congress on Politic, Economic and Social Studies)(No. $3)$.

Patrick, C. J., Fowles, D. C., \& Krueger, R. F. (2009). Triarchic conceptualization of psychopathy: Developmental origins of disinhibition, boldness, and meanness. Development and Psychopathology, 21, 913-938.

Paulhus, D. L., \& Williams, K. M. (2002). The dark triad of personality: Narcissism, Machiavellianism, and psychopathy. Journal of Research in Personality, 36, 556-563.

Paulhus, D. L., Hemphill, J. F., \& Hare, R. D. (2012). Self-Report Psychopathy scale (SRPIII). Toronto: Multi-Health Systems.

Paulhus, D. L. (2014). Toward a taxonomy of dark personalities. Current Directions in Psychological Science, 23(6), 421-426.

Penke, L., Denissen, J. J. A., \& Miller, G. F. (2007). The evolutionary genetics of personality (target article). European Journal of Personality, 21, 549-587.

Pinel, P. (1962). A treatise on insanity (D. Davis, Trans.). New York, NY: Hafner. (Original work published 1806).

Rank, O. (1929). Beyond psychoanalysis. Psychoanalytic Review, 16(1), 1-11.

Reich, W. (1933). The Mass Psychology of Fascism, translated by Vincent R. Carfagno.

Reidy, D. E., Zeichner, A., \& Seibert, L. A. (2011). Unprovoked aggression: Effects of psychopathic traits and sadism. Journal of Personality, 79, 75-100.

Rhodewalt, F., \& Peterson, P. (2009). Narcissism. In M. R. Leary \& R. H. Hoyle (Eds.), Handbook of individual differences in social behavior (pp. 547-560). New York, NY: Guilford Press.

Rogoza, R, Kwiatkowska, MM, Kowalski, CM, Slaski, S. (2018) A brief tale of the two faces of narcissism and the two facets of pride. Personality and Individual Differences; 126: 104-108. 
van Geel, M., Goemans, A., Toprak, F., \& Vedder, P. (2017). Which personality traits are related to traditional bullying and cyberbullying? A study with the Big Five, Dark Triad and sadism. Personality and Individual Differences, 106, 231-235.

Wai, M., \& Tiliopoulos, N. (2012). The affective and cognitive empathic nature of the Dark Triad of personality. Personality and Individual Differences, 52, 794-799.

Wastell, C. A., \& Booth, A. 2003. Machiavellianism: An alexithymic perspective. Journal of Social and Clinical Psychology, 22: 730-744.

Watson, P. J., Grisham, S. O., Trotter, M. V., \& Biderman, M. D. (1984). Narcissism and empathy: Validity evidence for the Narcissistic Personality Inventory. Journal of Personality Assessment, 48, 301-305.

Williams, K. M., Paulhus, D. L., \& Hare, R. D. (2007). Capturing the four-factor structure of psychopathy in college students via selfreport. Journal of Personality Assessment, 88, 205219.

Wilson, D. S., Near, D., and Miller, R. R. (1996). Machiavellianism: A synthesis of the evolutionary and psychological literatures. Psychological Bulletin, 119, 285-299.

Wink, P. ( 1991 ). Two faces of narcissism. Journal of Personality and Social Psychology, 61, 590597.

Wu, J., \& Lebreton, J. M. (2011). Reconsidering the dispositional basis of counterproductive work behavior: The role of aberrant personality. Personnel Psychology, 64(3), 593-626. 